\title{
An extremely rare case of ovarian abscess in third trimester of pregnancy managed by successful vaginal birth and review of literature
}

\author{
Anh Dinh Bao Vuong, Phuc Nhon Nguyen*
}

Department of High-risk Pregnancy, Tu Du Hospital, Ho Chi Minh City, Vietnam

Received: 12 January 2022

Accepted: 03 February 2022

\section{*Correspondence:}

Dr. Phuc Nhon Nguyen,

E-mail: docternhon@gmail.com

Copyright: (c) the author(s), publisher and licensee Medip Academy. This is an open-access article distributed under the terms of the Creative Commons Attribution Non-Commercial License, which permits unrestricted non-commercial use, distribution, and reproduction in any medium, provided the original work is properly cited.

\begin{abstract}
Ovarian abscess (OA) in pregnancy is actually rare occurrence, almost unheard, which associated with poor prognosis for mother and fetus. This diagnostic dilemma is often difficult to be elucidated because of anatomical changes in pregnancy. It was established incidentally by obstetric ultrasound or during cesarean section performed for an obstetric indication. Specially, the presentation of adnexal abscess is very hard to distinguish from appendical abscess. In this report, we presented a 20-year-old woman (G0P0) at 33-34 weeks of gestation was admitted to the clinic of our hospital with a pelvic abnormal tumour accompanied by fetal growth restriction. The patient was indicated for serial laboratory examination, which showed a right abnormal adnexal mass. At hospitalization, the patient was mostly asymptomatic so she was followed by medical treatment and by an expectant management. The surveillance was strictly controlled without complications, except intrauterine growth restriction associated with pregnancy. The patient received a conservative management and gave a well-being infant at 36-37 weeks of gestation by vaginal delivery. Twelfth days after delivery, she underwent a laparoscopic operation to remove the abscess mass. Preventive treatment is also a major importance. This report describes the clinical features and results of the case with an ovarian abscess detected in the 3 rd trimester without adverse sequelae and compared to the recurrent knowledge based on the literature regarding the advanced management of OA involved in pregnancy. Through this report, we aim to carry out a literature review in order to discuss these clinical manifestations of OA, optimize the importance in definitive diagnosis and underline the appropriate treatment of an individual case.
\end{abstract}

Keywords: Ovarian abscess, Adnexal mass, Pregnancy, Conservative management, Intrauterine growth restriction, Laparoscopy

\section{INTRODUCTION}

Tubo-ovarian abscess (TOA) is one of the major and serious late complications of acute salpingitis and occurs in as many as $15 \%$ of women with Pelvic inflammatory disease (PID). ${ }^{1}$ Understandably, TOA is defined as consequence of a previously untreated or inadequately treated acute pelvic infection. PID is a consequence of an ascendant infections from the lower part of the genital tract. Most of the cases, it is usually caused by polymicrobial agents, including sexually transmitted infections. ${ }^{2-5}$ In pregnancy, cervical mucus plug and intact amniotic membrane protect against ascending infection, therefore, TOA is an uncommon complication in pregnant women. It can cause to rupture and poor condition, particularly, in reproductive age women. The delayed treatment lead to poor prognosis for pregnancy. ${ }^{6,7}$

TOA in the $2^{\text {nd }}$ trimester or $3^{\text {rd }}$ trimester of pregnancy is actually rare. Most reported cases of TOA appeared in the $1^{\text {st }}$ trimester. ${ }^{8}$ By 1977 only 12 cases of TOA occurring late (including $2^{\text {rd }}$ and $3^{\text {rd }}$ trimester) had been described in the literature. Brindeau in 1917 is thought to have described the first such case. Because of its rarity, TOA is not often considered in the differential diagnosis of an acute abdomen in late pregnancy, the diagnosis often being 
made after laparotomy. ${ }^{9}$ The clinical manifestations are diverse, ranging from no symptoms to severe pelvic pain, with poor correlation between the intensity of symptoms and the severity of tubal inflammation. ${ }^{1}$ The main signs and symptoms are low abdominal pain, purulent cervical discharge, cervical tenderness, dyspareunia and hyperthermia. The triad of fever, leukocytosis, and diarrhea should alert clinicians to the possibility of TOA formation in patients with PID. ${ }^{10}$ There is usually elevation of the inflammatory serum parameters, such as leukocytosis with neutrophil and elevated C-reactive protein (CRP). At ultrasound, there may be no abnormal finding or images suggestive of TOA. ${ }^{2-5}$

However, the patients could be completely asymptomatic. Due to the fact that not all pelvic abscesses are diagnosed preoperatively and are associated with minimal signs of infection, definitive diagnosis is usually possible intraoperative. ${ }^{11}$

Pathologic processes that have findings similar to those of PID include endometriosis, adnexal torsion, ruptured hemorrhagic ovarian cyst, adnexal neoplasms. PID should be also differentiated from secondary inflammation of the fallopian tubes as a result of non-gynecologic processes such as appendicitis, diverticulitis or urinary tract infection. ${ }^{1,12,14}$ Typically, differential diagnosis of PID associated with pregnancy depends on onset time. In $1^{\text {st }}$ trimester, we need to exclude ectopic pregnancy, miscarriage.

In $2^{\text {nd }}$ and $3^{\text {rd }}$ trimester, it is absolutely necessary to separate from symptoms of preterm birth and amniotic infection. ${ }^{15}$ Therefore, diagnosis of adnexal abscess is based on clinical characteristics, infected serum and further useful imagine tools including ultrasonography, Computed tomography (CT) and Magnetic resonance imaging (MRI). These help to be enabled early diagnosis of this unusual complication of pregnancy. ${ }^{2}$ Commonly, MRI play a key role in confirming this ambiguous diagnosis. Otherwise, it costs more expensive than sonography. So, ultrasonography is usually indicated for the first-line imaging modality of evaluation. Adnexal masses during pregnancy required operation with a frequency from 1 in 81 to 1 in 2500 live births. Sonographical-guided drain and minimally invasive intervention combined with antibiotic therapy are recommended prior to operation during pregnancy albeit there is current absence of evidence on patient management. ${ }^{16}$ Reports of pelvic abscess complicating was rare, reviews of literature realized only a few cases of pregnancy reaching term. In this article, an unusual case with asymptomatic abscess were managed successfully during pregnancy by conservative treatment.

\section{CASE REPORT}

A 20-year-old primigravida at 33 weeks 3 days of gestation was transferred to the gynecological clinic unit of our hospital with abnormal findings on the right iliac fossa and of lower abdominal pain. Her menarche was at 15, menstrual cycle was irregular and menstrual amount was moderate with infrequent dysmenorrhea. Family history was non-specific. She had no medical history of disease and no past history suggestive of tuberculosis, pelvic or abdominal surgery, and appendicitis before pregnancy. Her past gynecological history was also irrelevant for PID. She achieved pregnancy naturally after getting married. The patient's expected date of delivery was $2^{\text {nd }}$ January 2022 so she was 33 weeks and 3 days of gestation at hospitalization.

At 21 weeks of gestation (28 $8^{\text {th }}$ August 2021), she had symptoms of abdominal tenderness, fever, vomiting and constipation. Sometimes, she felt painful, discomfort and burning of urination unfrequently. The women went to the cottage hospital and she was informed an ovarian cyst measuring $63 \mathrm{~mm}$ in diameter. No adnexal mass was noted on ultrasonography. At this time, the patient was not indicated for treatment. Because of latent pain, she took oral anti-inflammatory drugs (danazym $10 \mathrm{mg}$, celecoxib $100 \mathrm{mg}$ ), oral antibiotic (nalidixic acid $500 \mathrm{mg}$ ) and some unknown tablets as auto-medication at home for a duration of 10 days. Clinical symptoms were improved gradually. At 22 weeks and 6 days of pregnancy $\left(7^{\text {th }}\right.$ September 2021), she went for an ultrasound examination and figured out a fibroids in the posterior wall of the cervix. Therefore, the patient was recommended to readmit for antenatal care at our hospital. Unfortunately, she vaccinated only 1 dose of vaccine against coronavirus and epidemic of COVID19 was spread out currently so she could not visit early at our hospital for antepartum investigation. On $11^{\text {th }}$ September 2021, she went for routine examination and discovered fetal growth restriction along with a mixed echo right iliac fossa tumor, sized about $98 \times 88 \mathrm{~mm}$ in diameter. Therefore, she was transferred to our hospital immediately.

On admission, the women was systemically well and clinically stable. Her vital signs were unremarkable including normal body temperature. Her blood pressure was $110 / 70 \mathrm{mmHg}$ and 86 beats/min, respectively. She was pale on examination. She had no symptoms of infection such as vomiting, diarrhea. On abdominal examination, no sign of peritonitis were detected. The uterus was corresponding to 33 week gravid uterus size. The tocolysis was not administered. There were no signs of fetal distress. There was also no sign of rupture of amniotic membranes by nitrazine test. Speculum examination showed only a whitish, viscous, homogenous vaginal discharge. Suspecting chorioamnionitis was excluded on clinic. Digital vaginal examination found the posterior cervix and the external os of cervix was opened lightly without cervical dilation or vaginal bleeding. On pelvic examination, a suspected right-sided pelvic mass about $10 \mathrm{~cm}$ in size was palpated.

At blood test, leukocyte: $19.200 / \mathrm{mm}^{3}$, neutrophil: $8.8 \%$, hemoglobin: $9.41 \mathrm{~g} / \mathrm{dl}$, platelet: $389.000 / \mathrm{mm}^{3}$ and CRP was $9.7 \mathrm{mg} / \mathrm{dl}$. Glycemia, urinalysis, liver function test and 
renal function test were within normal limit. Her HIV and hepatitis B serology were negative. On abdominal examination, no sign of peritonitis was detected. After 14 days of medical treatment, leukocytosis was significantly decreased to $10.85 / \mathrm{mm}^{3}$. Her investigations also showed moderate anemia with hemoglobin of $8.9 \mathrm{~g} / \mathrm{dl}$. CRP reduced to $7.2 \mathrm{mg} / \mathrm{l}$. Markers of malignant ovarian tumor were at normal limit: Alpha-feto protein (AFP): $208(<7)$ $\mathrm{ng} / \mathrm{ml}$, cancer antigen-125 (CA-125): $16.4(\leq 35) \mathrm{UI} / \mathrm{ml}$, human epididymal protein 4 (HE-4): 45.6 ( $\leq 70) \mathrm{pmol} / \mathrm{l}$, Risk of ovarian malignancy algorithm (ROMA score): 6.1 $(<25.3 \%)$.

Cervical culture was not obtained because it was not included in the routine patient assessment at our department. She has no previous result of Group B streptococcus (GBS) test and current test for culture of Staphylococcus from vaginal swab was negative. Parameters of cardiotocography were normal, according to classification of the American College of Obstetricians and Gynecologists (ACOG) in 2009, except for assessment of uterine contraction was noted from 4 to 5 frequencies within 10 minutes with strength of contractions was variable from 15 to $25 \mathrm{mmHg}$. Fetal assessment of repeated ultrasound features revealed a restriction of fetal growth corresponding to 33 week gestation, weighed 1620 gram, estimated under $1^{\text {st }}$ percentile of Hadlock formula, increased umbilical pulsatility index, reduction of middle artery of brain and Cerebroplacental ratio (CPR).

A standard transvaginal ultrasound scan was done and revealed a suspected solid multilocated right ovarian cyst with diffuse internal heterogeneous echoes and size was about $90 \times 140 \mathrm{~mm}$. Ultrasound showed without evidence of free fluid in the cul-de-sac (Figure 1).

MR imaging found an abnormal formation with large tubal structures was $140 \times 74 \times 107 \mathrm{~mm}$ in dimension, arising from right iliac fossa to the $\mathrm{Cul}$ de sac. Right ovary was not observed. This thicked-wall lesion contained purulent fluid which had hetero signal intensity on T1/T2-weighted MRI along with surrounding fat infiltration.

The patient was administered of corticosteroid for fetal lung maturity. She was also given intravenous antibiotics of cefovidi $1 \mathrm{~g}$ every $12 \mathrm{~h}$ and metronidazole 500 milligram every $8 \mathrm{~h}$. In the event of Intrauterine growth restriction (IUGR), she was planned for an elective induction at 36-37 weeks of gestation. She underwent an induction labor by membrane sweeping initially. Because of unfavorable cervix, Bishop Score was evaluated at 2 points. We adjusted to induct by single balloon of Foley catheter, followed by augmentation with oxytocin drip ( 5 units in $500 \mathrm{ml}$ Ringer lactate at the rate of 8 drops per minute in escalating doses) in 9 hours. Finally, she delivered a healthy infant by vaginal birth. Blood loss was estimated approximately $120 \mathrm{ml}$. Newborn baby's weight was $2000 \mathrm{~g}$, with an Apgar score of 8/10 at one min. Baby had no symptoms of infection evaluated by neonatal specialist.
During postpartum period, she remained apyrexial and normotensive. However, her blood examination showed a significant increase of leucocytes up to $25.000 / \mathrm{mm}^{3}$. She was received a repeated regimen of combined antibiotics including cefovidi, gentamycin and metronidazole. After 24 hours of therapy, she was exanimated further by routine blood example. Leucocytes reduced gradually to $9000 / \mathrm{mm}^{3}$. Ultrasound revealed uterus in the normal condition and abnormal right-side mass remained the same size compared to previous ultrasound. Following counseling and discussion with the patient, we made a decision of conservative management with medical treatment. Both mother and baby were discharged within 3 days postpartum in a good healthy condition. She was organized to return our hospital for check-up later. The patient discharged home on oral antibiotics of $3^{\text {rd }}$ generation cephalosporin and metronidazole.

After 10 days of outpatient follow-up, the patient revisited to our hospital for surveillance without signs of infection. On radiological image, we realized the adnexal mass was the same size compared with initial investigation accompanied by a retained tissue in uterine cavity. Abnormal pelvis mass was revealed with average vascularization and measured $106 \times 72 \times 68 \mathrm{~mm}$ in size by sonography. Due to unchanged measurement of size after follow-up, we finally made a decision to interfere with a laparoscopic surgery under general anesthesia.

Although abscess removal is difficult to be resolved by laparoscopy in most of cases, but this minimally invasive procedure applied since 1990's holds many well-accepted practical advantages. These include less surgical trauma, faster recovery after the operation, lower rate of complications, less postoperative intraperitoneal adhesion, reduced incidence of thrombophlebitis and smaller scar in comparison with traditional laparotomy. ${ }^{17}$ In reality, this surgery is also encountered widely at our hospital. Intraoperative exploration revealed clear abdominal cavity, uterus equals to gestational age of 12 weeks. The appendix was normal. Left adnexal structure and right fallopian tube appeared likely normal, the right ovary was not found (Figure $3 \mathrm{~A}$ ). A $10 \times 11 \mathrm{~cm}$ right sided abscess originated suspiciously from ovary extending into the Pouch of Douglas. Additionally, adhesion between the loops of intestine, the uterus, and the ovarian tissue was observed without vascularization. During adhesiolysis, the abscess wall inadvertently got ruptured. In total, approximately 80 $\mathrm{ml}$ of yellow-brown pus was drained during the process of dissection. A specimen of abscess mass was investigated for histopathological examination and purulent fluid was collected for microbiological study. The normal ovarian parenchyma was separated difficultly to abnormal tissue. Therefore, a part of right ovarian removal compatible to pathologic tissue was performed carefully followed by thorough peritoneal lavage with saline solution. The abdomen was extensively washed out and a pelvic drainage was inserted. In addition to laparoscopy, we performed promptly an intrauterine suction by Karman curette due to retained tissue in the postpartum period. 
After surgical procedure, intravenous antibiotics were administered including cefovidi and Metronidazole for a 7-day course. The drainage output diminished significantly. Repeat ultrasonography found a heterogeneous echo mass which collected fluid and formed as pseudocytes about $84 \times 53 \times 63 \mathrm{~mm}$ in dimension in the $\mathrm{Cul}$ de sac. Otherwise, the patient remained afebrile, her white blood count normalized and inflammatory marker was also normal. Therefore, we have not yet thought a persistent abscess in present case. Histopathological examination of surgical tissue showed a marked area of inflammatory infiltration, suggested a chronic inflammatory disease and confirmed an ovarian abscess. She was in good condition after 7 days of hospitalization, except nausea, vomiting which was improved rapidly by medicaments. Bacterial organisms were not grown in the culture obtained from the pus of ovarian abscess. It could be explained by good response of empirical antibiotic administration in this case. The treatment prevented effectively the development of abscess mass. She was scheduled for follow-up 1 month later with postoperative period uneventful.
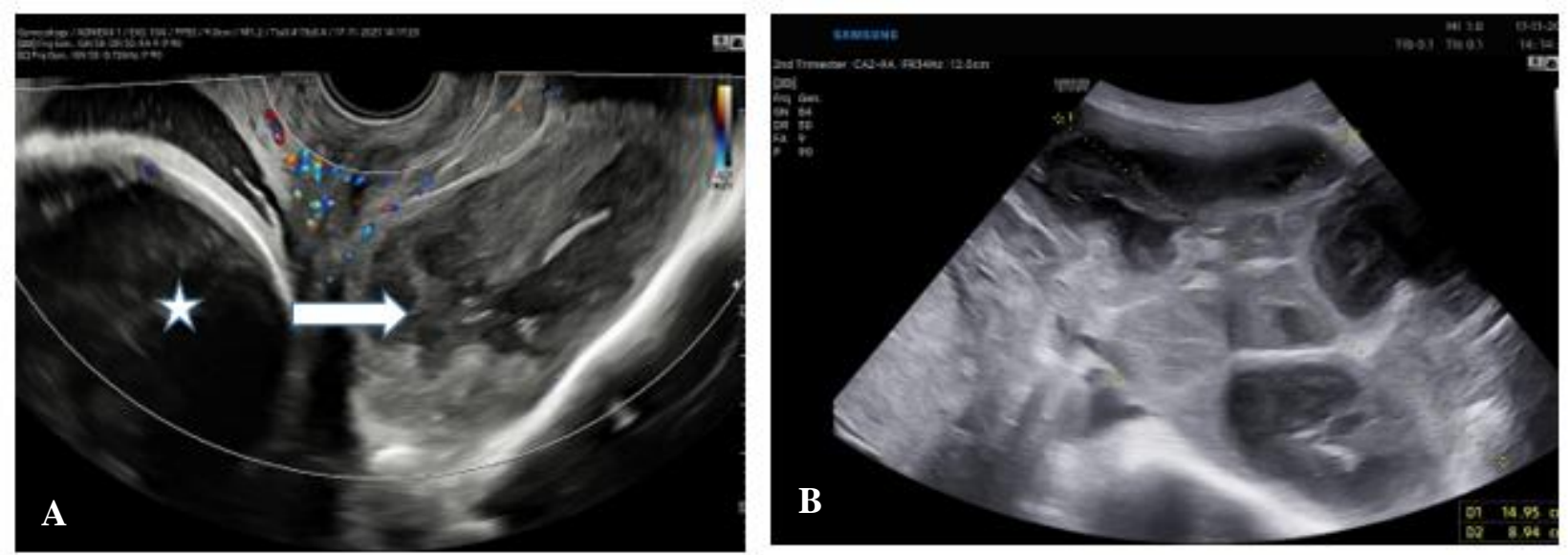

Figure 1: Image of ovarian abscess on ultrasonography (A) pelvic ultrasonography revealed and confirmed a viable fetus of 33-34 weeks gestation (white star) and a solid mass with diffuse internal echoes in the right adnexal region (white arrow) without any evidence of free fluid in the cul-de-sac; (B) A $14.95 \times 8.94 \mathrm{~cm}$ diameter solid and cystic mass with an irregular contour was revealed in the right adnexal region with tubal structure was totally extended.
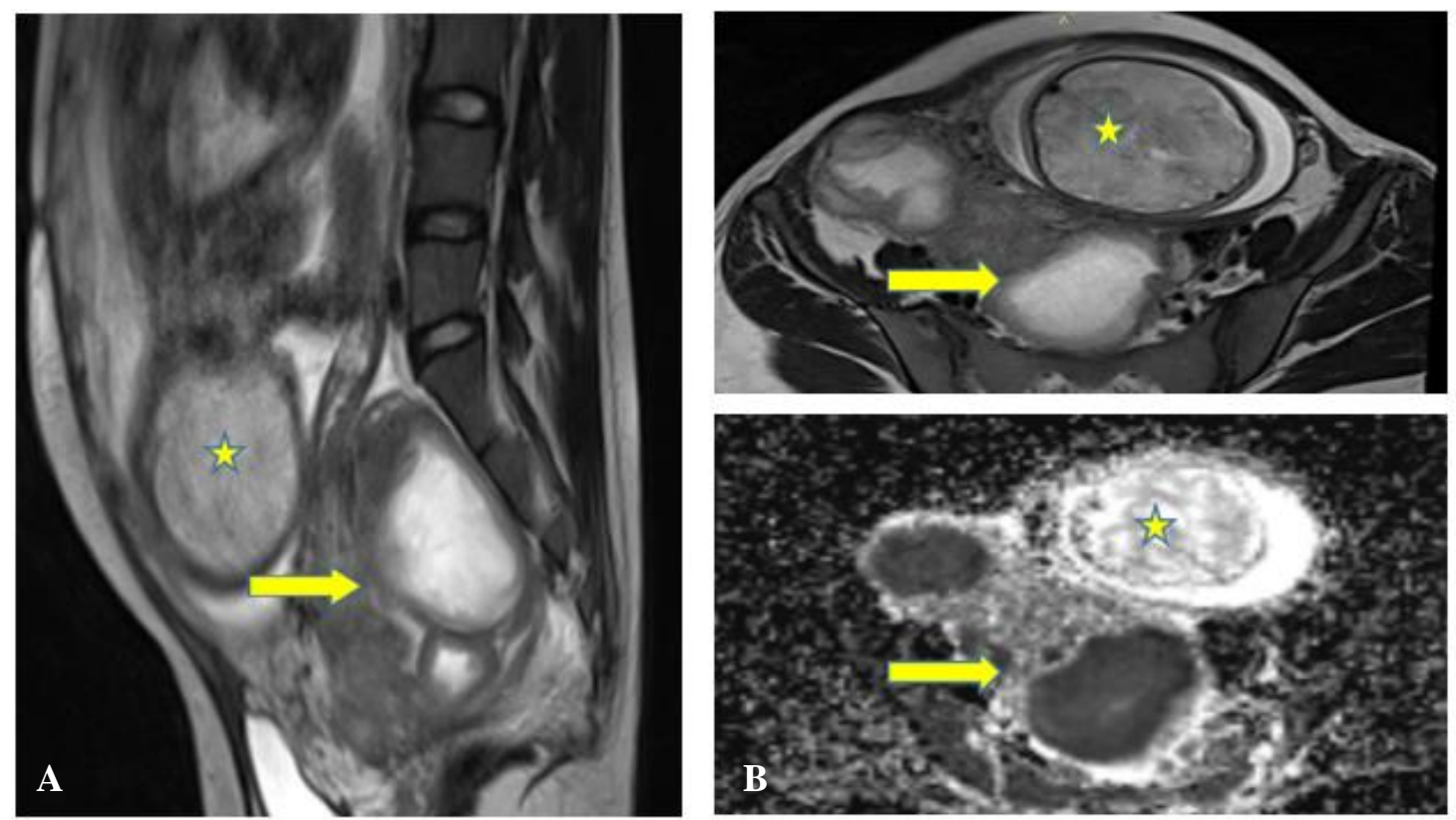

Figure 2: Magnetic resonance images of ovarian abscess (A) abdominal MRI showed a single fetus in the vertex plane (yellow star) along with a large prominent cystic lesion in pelvis with internal septations measuring $74 \times 107$ $\mathrm{mm}$ in axial dimension and $140 \mathrm{~mm}$ craniocaudally. This mass contained purulent fluid (yellow arrow); and (B) a transverse view of the large complex pelvic cystic lesion on T1/T2 weighted scans. Pelvic MRI figured out fetal head (yellow star) and right tubo-ovarian abscess (yellow arrow) along with fat stranding. 

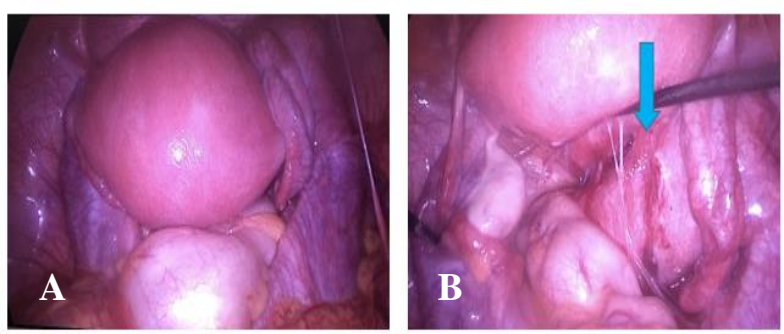

Figure 3: Photograph of laparoscopy (A) on photograph of explorative laparoscopy, peritoneal cavity appeared totally normal including both fallopian tubes. No abnormal mass was observed at this view; and (B) right posterior side of uterus, an adhesive thick-walled mass about $8 \times 10 \mathrm{~cm}$ in size was found. This edematous mass (blue arrow) was likely arising from the right ovary extended/ enhanced to the Cul de sac (the Pouch of Douglas).

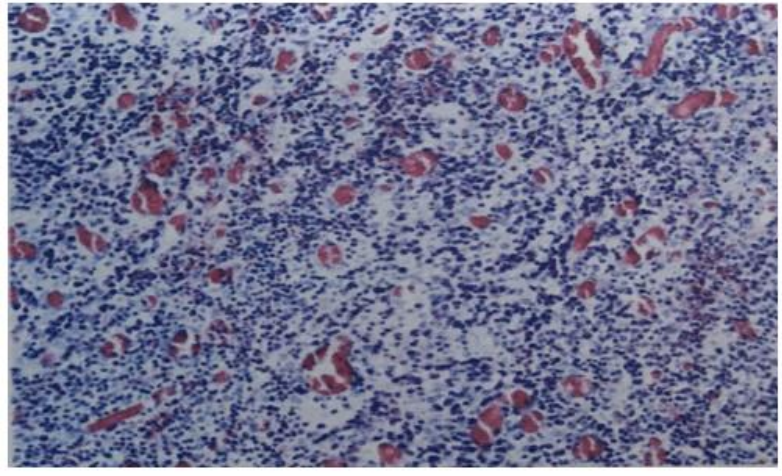

Figure 4: Photomicrograph of histopathological specimen observed by microscope- histology of the abscess masses shows sheets of foamy macrophages admixed with lymphocytes and neutrophils.

\section{DISCUSSION}

An ovarian abscess is primarily an infectious process of the ovary which differs from the tubo-ovarian abscess in which involvement of the ovary is secondary to the tubes. ${ }^{18}$ Aitken was the first person who gave the description of primary OA in 1869 . Vimala. $\mathrm{N}$ had reported the first case of primary OA in association with pregnancy in 2004. ${ }^{16}$ Commonly, many authors already reported around 10 cases of TOA in the $3^{\text {rd }}$ trimester in the literature by 2009. ${ }^{19,20}$

Ascending infection in association of PID is the most important mode of infection in nonpregnant women. The pathogens of TOA are variable. Organisms isolated from TOA seem to belong to the facultative anaerobe Enterobacteriaceae family (Escherichia coli, Proteus, Klebsiella) and anaerobic peptostreptococcus, streptococcus or actinomyces. ${ }^{6}$ However, TOA of unknown origin has also been reported. Even though some authors already reported different cases of TOA in virgin and postmenopausal women who have no more risk of sexually transmitted disease. ${ }^{21}$

During pregnancy, pelvic infection occurs independently from pregnancy or the infection may exist before the pregnancy. Proposed pathogeneses of OA during pregnancy remains poorly understood. Pelvic infection also occurs in the puerperium if there is infection of the birth canal during or following parturition. ${ }^{22}$ Friedman and Bobrow have proposed some mechanisms for infection of ovaries during pregnancy: (a) haematogenous spread from a distant fold, as in pelvic tuberculosis; (b) lymphatic spread especially from infected vagina and cervix; (c) infection of a previously existing ovarian cyst; and (d) flare-up of a previous infection. Since infection needs about 6 weeks to 6 months to develop up to the stage of an abscess, the germ might have been contracted before or during the fertile period as suggested by James et al. ${ }^{23,24}$ Most of cases were unilateral, as in our case, probably explained by a 'flare-up' of a previous inflammation.

The immunitary system of pregnant women is different from which of nonpregnant women. The suppressed immune system is necessary to allow mothers to tolerate genetically fetal tissues. ${ }^{19}$ Endometriosis may increase the risk of abscess formation, because locally impaired immunity in the pelvic cavity makes the patient vulnerable to infection. Previous laparotomy, structural genital anomalies, gonococci attached to motile spermatozoa, and the use of assisted reproductive technology are known risk factors for pelvic abscess during pregnancy. Many authors have already mentioned in TOA following transvaginal oocyte retrieval, intrauterine insemination, in vitro fertilization and embryo transfer. , $^{6,25,26-28}$

Surely, it is difficult to elucidate the exact mechanism of pelvic infection in our case. Firstly, she complained that she had irregular symptom of dysmenorrhea but she did not investigate before pregnancy. Yellow-brown fluid from abscess mass is likely to endometrial cyst. Therefore, we hypothesized that she actually had an ovarian endometrioma which became infectious. The infection might have flared up recently and presented in the $3^{\text {rd }}$ trimester of pregnancy. This complication was approved in the report of Modak et al. ${ }^{29}$ Secondly, she had some symptoms of PID such as fewer, lower abdominal pain and of urinary infection around 20 weeks of gestation. She took antibiotic by herself at home so inflammation was limited and developed gradually to abscess. Theoretically, we were uncertain if she had formation of ovarian abscess arising from this causative hypothesis. Dysuria may be a sign of urinary infection but also a symptom of pelvic abscess. Large tubo-ovarian abscesses can cause hydronephrosis and hydroureter with urinary retention. ${ }^{22}$ The preoperative diagnosis of tubo-ovarian abscess in pregnancy remains extremely difficult. Because of this, it has been suggested that some patients may have been treated with antibiotics which have coincidentally cured the PID. ${ }^{9}$ Interestingly, this coincidence was similar to our case. 
Review of the case reports in the literature have revealed only a few cases of pregnancy reaching term with adverse perinatal outcome. ${ }^{6}$ Our patient is one of the rare cases of primary OA managed nearly to term and firstly successful to delivery by vaginal. Almost cases were delivered by $\mathrm{C}$ section due to maternal or fetal indication (Table 1 and 2). ${ }^{7,19}$

At laparotomy, there was no clarified evidence of spread of infection from adjacent organs, fallopian tubes were likely normal. Thus, the proposed mechanism in our patient could be flared up of old infection which located at ovarian tumour previously. Intraoperative finding of adhesion between the loops of intestine, the uterus, and the ovarian tissue indicated the chronic nature of the disease. At hospitalization, although her glycaemia was stable, the patient had been diagnosed for gestational diabetes after 24 weeks. So she was followed the diet of diabetes during pregnancy. However, the patient did not have data of glycaemia at her gestational period so we thought gestational diabetes contributed probably to one of the risk factor for inflammatory condition.

The patient with an adnexal abscess in pregnancy usually shows variable symptoms. Abdominal pain encountered during pregnancy should be differentiated from various possible causes, including physiologic effects of pregnancy and pathologic conditions related or not related to pregnancy. Physiologic conditions in pregnancy include round ligament pain, uterine torsion and Braxton-Hicks contraction. ${ }^{6}$ In our case, the patient had some slight contractions at admission. This may be Braxton-Hicks contractions or an irritation from infection of neighboring organ. Some reports noted that the pelvic mass may be a cause of spontaneous abortion or preterm birth because of uterine contraction. ${ }^{26}$ In reality, even if we had no use of tocolytic administration, she didn't progress to labor. Therefore, we considered these weak contractions were physiological.

In our case, before visiting our hospital, the patient was misdiagnosed as ovarian tumour and fibroma. The management was delayed for a couple of weeks and in result, ovarian abscess developed larger dramatically. This mimicking diagnosis was also reported by some authors previously. ${ }^{30,31}$ Almost cases showed symptoms or signs during pregnancy, which allowed intervention immediately. ${ }^{32}$ The common signs of TOA include fever, pelvic pain and vomiting. Additional symptoms of TOA include vaginal discharge, irregular vaginal bleeding, urinary symptoms, nausea and vomiting. About $20 \%$ of patients with TOA may be afebrile or have a normal leukocyte count, which represents a significant minority. $4,5,33$

In most cases, TOA during pregnancy is not suspected preoperatively, definitive diagnosis is made during laparotomy or C-section. ${ }^{8,34}$ Surprisingly, similar to almost published cases, no signs or symptoms suggested to pelvic abscess were observed during hospitalization in our patient. Our case of abscess mass discovered by radiological modalities such as ultrasound and MRI.

On hematologic findings, WBC was abnormally increased. Costicosteroid was administered in her treatment for pulmonary maturity of fetus. Some studies reported this agent could lead to increase WBC lightly. ${ }^{35}$ However, we punctured for laboratory findings before injection of this drug. Therefore, we assured that high WBC related to infectious condition and we carried out further investigation. Obviously, leukocytosis was decreased substantially following antibiotic therapy in 24-48 hours. After delivery, WBC was increased dramatically. This progression is presented physiologically in some studies and reduced gradually during 24 hours after labor. ${ }^{36,37}$ Hemoglobin concentration was low significantly. So the patient was in anemia condition during pregnancy, this may be consequence of long-lasting infection.

Ultrasound could not be effective to detect this complication in late gestation due to an enlarged uterus. OA may not be diagnosed by routine obstetric sonography unless the symptoms are suspected. ${ }^{6}$ In our case, the OA presented initially as a large unilocular cystic mass with homogenous internal echoes, and demonstrated slightly thicker walls with increased vascular flow later. There is often an overlap of appearances between OA with other entities. The sonographic appearance of OA can resemble and be mistaken for other cystic ovarian masses including an endometrioma, dermoid cyst or infected leiomyoma. ${ }^{31}$ Otherwise, this imaging modality could be reproducible to follow the size of mass. Therefore, ultrasound should be considered as a complementary examination technique used in conjunction with clinical and laboratory findings. ${ }^{4,5,33}$

MRI is the radiological modality of choice due to the absence of fetal radiation risk and it is better than $\mathrm{C}$ for evaluating the soft tissue. Magnetic resonance image had a great value for evaluation, especially, in pregnancy. ${ }^{12,38}$ In our case, MRI played a key role in challenging diagnosis. The MRI of TOA is described as a thick-walled adnexal mass with low signal intensity contents on T1weighted images and high signal intensity on T2-weighted images. This appearance is variable, however, and there are cases of TOA demonstrating intense or increased signal intensity on T1-weighted images, and some have heterogeneous signal intensity on T2-weighted images. ${ }^{1}$

Based on previously published studies, the incidence of ovarian masses detected in pregnancy is estimated to be 12\%. Particularly, ovarian malignancies are rare during pregnancy. The occurrence rates were $0.93 \%$ (87/9375) ovarian cancers per total number of ovarian masses diagnosed during pregnancy, and 0.0179 ovarian cancers per 1000 deliveries. ${ }^{39}$ Nevertheless, assessment of obstetric ultrasound, we found the patient had a moderate vascularized image of multilocated mass originated from right ovary. Therefore, we needed to investigate by immunitary serum. Fortunately, carcinogenic markers 
such as CA 125, HE4, AFP, ROMA score were in normal limit. CA-125 may be increase slightly in these circumstances. ${ }^{22,40,41}$ The treatment of pelvic abscesses during pregnancy is difficult. Prolonging gestational duration in the context of infection situation is a challenge of treatment. Surgical interventions and broad-spectrum antibiotics are all choices for treatment. Routine TOA drainage leads to a significant decline in levels of infectious markers such as leukocyte count, CRP and procalcitonin levels, within 48 hours of the surgery. Routine surgical abscess drainage appears as a safe and effective way of treating patients with TOA. ${ }^{42}$ Patients with tubo-ovarian abscess that does not respond to antibiotics should undergo surgical drainage.$^{43}$ Gjelland et al reported that ultrasound-guided transperitoneal or transvaginal drainage of abscess allows antibiotics to control the infection more effectively. Since rupture of the abscess during pregnancy appears commonly to lead to fetal death.

This situation requires an aggressive and primarily surgical approach in order to minimize catastrophic sequelae. The abdominal cavity should be drained either vaginally or through bilateral lower quadrant stab wounds. Some authors have more recently described cases of TOA late in pregnancy where conservative surgery was practiced. In these cases only unilateral salpingooophorectomy was performed with good maternal results. ${ }^{9}$ Unruptured abscess may be treated by broad-spectrum intravenous antibiotics at least 72 hours before surgery. ${ }^{16}$ It has been the standard recommendation that any mass above $6 \mathrm{~cm}$ which persists to the $2^{\text {nd }}$ trimester should be removed by laparotomy, to prevent complications such as torsion, rupture, obstruction of labor and to rule out ovarian cancer. ${ }^{44}$ In recent years, laparoscopy in pregnancy has been a feasible option. The advantages of laparoscopy are obvious, including outpatient management or shorter hospital stay, reduced recovery time, less pain, and decreased cost. ${ }^{45}$ Controversially, one group of young women, those who are pregnant, have not yet benefitted from the advances of operative laparoscopy. ${ }^{44}$ Surgical intervention may increase the susceptibility of pregnant women, traumatic procedure might increase the risk of uterine irritability, resulting in postoperative spontaneous abortion or premature labor, adding anxiety to the patient. Therefore, it is appropriate to manage by considering both the infection severity and gestational weeks when treating pelvic abscess during pregnancy.

Exceptionally, laparoscopy is limited in the $3^{\text {rd }}$ trimester due to an increased risk of injury to the enlarged uterus. In addition, it was difficult to remove totally the abscess when the enlarged gravid uterus was in the abdominal cavity. ${ }^{19}$ In our case, young primigravida was discovered unruptured ovarian mass at 33-34 weeks of gestation so we decided to follow the conservative management. Unlikely our case, most of the cases of TOA in pregnancy reported in the literature were managed operatively as soon as they were recognized during surgery. Almost reports of TOA in non-pregnant women, drain placement combined with antibiotic therapy will promote efficacy of drug. ${ }^{4}$ However, we did not perform a drainage procedure because of the possible development of sepsis. Additionally, the patient was admitted to our hospital lately. Thicked-wall abscess mass was large in size respectively. So drainage would increase further the risk of peritonitis, intestinal trauma, septicemia and intrauterine fetal death. Finally, we made a decision to manage by combined antibiotics course, aim to limit the infectious progression. Since microorganisms frequently cultured include E coli, Bacteroides spp, Peptostreptococcus spp, and aerobic Streptococcus spp. Thus, broad-spectrum antibiotic coverage is selected for initial management of women with unruptured TOA. ${ }^{4}$ First line of antibiotic therapy for treatment of PID is ceftriaxone (or cefoxitin)+doxycycline+metronidazole. ${ }^{46}$ However, we did not use of doxycillin because this medicament belongs to tetracyclines group labeled as category D. Therefore, this drug is not recommended in pregnancy and in childbearing period if the patient has no life-threatening risk. ${ }^{47}$ On clinical aspect, we noted that the patient had no signs of infection, moreover, on laboratory examination, leucocytes and CRP was decreased progressively. So we thought that patient had response to medical treatment quickly. Due to large solid mass, so we did not hope to reduce the size of mass in a couple of weeks. Our purpose was to prevent the spread out of infection.

The fetus was diagnosed with intrauterine growth restriction. This situation was probably the consequence of chronic infection which influenced to her diet condition. And the blood must supply for the huge lesion adjacent to uterus. Classification of FGR equals to $1^{\text {st }}$ grade in this case and gestational termination in this situation was 37 weeks of gestation followed recommendations by the International Federation of Gynecology and Obstetrics (FIGO), the American College of Obstetricians and Gynecologists (ACOG) ${ }^{48,49}$ So we attempted to take into account of individualized treatment and made an induction of labor at 36-37 gestational weeks. At delivery, we also made a trial of labor to give birth by vaginal. In result, the women delivered a healthy female infant and she was in safe condition.

Unfortunately, after 10 days of outpatient surveillance, the mass persisted in the same size with initial measurement. Some studies reported that abscess mass more than $6 \mathrm{~cm}$ should be resolved by surgery because of failed risk for medical treatment. ${ }^{40,41,50,51}$ Therefore, our patient was planned for laparoscopy following counseling. We removed only abscess mass to preserve reproductive organs of women of child-bearing age. The patient with unilateral involvement managed with the preservation had a favorable outcome.

Drain placement is required importantly to prevent postoperative recurrence. ${ }^{19}$ Histopathological result is gold evidence for diagnosis of ovarian abscess. In our case, it is accurately compromised with a chronic infection (Figure 4). Bacterial culture did not find the present of any agent 
in present case. Cultures of the pus most frequently grew streptococcus or anaerobic organisms. However, cultures could be sterile. This result was similar in some previous reports published by Han et al., ${ }^{7,19}$ The effective treatment may limit substantially the development of bacteria in this case.

Table 1: Features and common symptoms of TOA in $3^{\text {rd }}$ of pregnancy. ${ }^{32}$

\begin{tabular}{|c|c|c|c|c|c|c|c|c|c|}
\hline$\frac{\vec{L}}{8}$ & 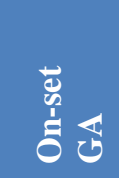 & $\stackrel{0}{\frac{0}{0}}$ & $\frac{0}{i n}$ & 名 & $\underbrace{0}_{0}$ & 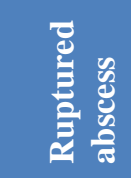 & 递 & 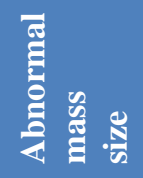 & 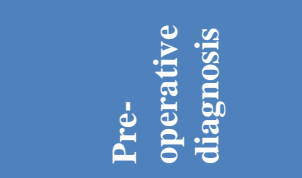 \\
\hline $\begin{array}{l}\text { Brindeau et } \\
\text { al, } 1917\end{array}$ & Term & $\mathrm{X}$ & $\mathrm{R}$ & Yes & Yes & $X$ & No & Yes & $\mathrm{X}$ \\
\hline $\begin{array}{l}\text { Cron et al, } \\
1924\end{array}$ & 31 & $\mathrm{X}$ & $\mathrm{L}$ & Yes & Yes & No & Yes & Yes & TO mass \\
\hline $\begin{array}{l}\text { Merajkar et } \\
\text { al, } 1940\end{array}$ & $7 \mathrm{~m}$ & No & $\mathrm{R}$ & Yes & Yes & No & Yes & Yes & $\begin{array}{l}\text { Peri-appendicular } \\
\text { abscess }\end{array}$ \\
\hline $\begin{array}{l}\text { Lowrie et al, } \\
1951\end{array}$ & $7 \mathrm{~m}$ & $\mathrm{X}$ & $\mathrm{R}$ & Yes & Yes & Yes & Yes & $\mathrm{X}$ & Placental abruption \\
\hline $\begin{array}{l}\text { Friedman et } \\
\text { al, } 1959\end{array}$ & $28 w$ & No & $\mathrm{R}$ & Yes & No & No & Yes & Yes & $\begin{array}{l}\text { Placental abruption } \\
\text { vs torsion of ovarian } \\
\text { cyst }\end{array}$ \\
\hline $\begin{array}{l}\text { Jafari et al, } \\
1975\end{array}$ & $41 \mathrm{w}$ & No & $\mathrm{L}$ & No & No & No & No & No & Fetal distress \\
\hline
\end{tabular}

Note: X: not informed; R: right, L: left, m: months, w: weeks.

Table 2: Interventions and outcomes of TOA during $3^{\text {rd }}$ trimester of pregnancy in literature. ${ }^{19}$

\begin{tabular}{|c|c|c|c|c|c|c|}
\hline Report & $\begin{array}{l}\text { Risk } \\
\text { factors }\end{array}$ & $\begin{array}{l}\text { Onset } \\
\text { GA }\end{array}$ & $\begin{array}{l}\text { Time of } \\
\text { intervention }\end{array}$ & $\begin{array}{l}\text { Surgical } \\
\text { intervention/ } \\
\text { procedure }\end{array}$ & $\begin{array}{l}\text { Maternal and } \\
\text { neonatal outcomes }\end{array}$ & Bacterial study \\
\hline $\begin{array}{l}\text { Lowrie } \\
\text { et al, } \\
1951\end{array}$ & None & $7 \mathrm{~m}$ & $7 \mathrm{~m}$ & $\begin{array}{l}\text { Laparotomy-excision } \\
\text { of diseased tube and } \\
\text { cornu of the uterus, } \\
\text { CS }\end{array}$ & $\begin{array}{l}\text { Live NB at GA } 7 \mathrm{~m} \text {, } \\
\text { but died within } 48 \mathrm{~h} \text {. } \\
\text { Abortion on } \\
\text { postoperative } 12 \mathrm{~h}\end{array}$ & $\begin{array}{l}\text { Escherichia coli } \\
\text { (pus) }\end{array}$ \\
\hline $\begin{array}{l}\text { Jafari et } \\
\text { al, } 1977\end{array}$ & None & $41 \mathrm{w}$ & $41 \mathrm{w}$ & $\begin{array}{l}\text { Laparotomy-CS, left } \\
\text { SO, right Pomeroy } \\
\text { tubal ligation }\end{array}$ & $\begin{array}{l}\text { Healthy NB at GA } 41 \\
\text { w, CS }\end{array}$ & $\begin{array}{l}\text { Peptococcus } \\
\text { (abscess) }\end{array}$ \\
\hline $\begin{array}{l}\text { Zwee- } \\
\text { mer et } \\
\text { al, } 1996\end{array}$ & $\begin{array}{l}\text { TVOR, } \\
\text { pelvic } \\
\text { surgery, } \\
\text { pelvic } \\
\text { adhesion }\end{array}$ & $\begin{array}{l}\text { After } \\
\text { delivery }\end{array}$ & $7 \mathrm{w}$ after $\mathrm{CS}$ & $\begin{array}{l}\text { Laparotomy-excision } \\
\text { of ovarian abscess }\end{array}$ & $\begin{array}{l}\text { Healthy NB at GA } 38 \\
1 / 7 \text { w, CS }\end{array}$ & $\begin{array}{l}\text { Peptococcus } \\
\text { (abscess) }\end{array}$ \\
\hline $\begin{array}{l}\text { Laohabu } \\
\text { ranakit } \\
\text { et al, } \\
1999\end{array}$ & None & $32 \mathrm{w}$ & $32 \mathrm{w}$ & $\begin{array}{l}\text { Laparotomy-CS, } \\
\text { hysterectomy, } \\
\text { bilateral SO, } \\
\text { appendectomy }\end{array}$ & $\begin{array}{l}\text { Healthy NB at GA } 32 \\
\text { w, CS }\end{array}$ & $\begin{array}{l}\text { Bacteroides } \\
\text { fragilis, } \\
\text { Peptostreptococ } \\
\text { cus (pus) } \\
\text { Klebsiella } \\
\text { pneumonia } \\
\text { (pus) }\end{array}$ \\
\hline $\begin{array}{l}\text { Erdem } \\
\text { et al, } \\
2002\end{array}$ & $\begin{array}{l}\text { Endomet } \\
\text { rioma, } \\
\text { pelvic } \\
\text { surgery }\end{array}$ & $34 \mathrm{w}$ & $34 \mathrm{w}$ & $\begin{array}{l}\text { Laparotomy-CS, right } \\
\text { SO }\end{array}$ & $\begin{array}{l}\text { Healthy NB at GA } 34 \\
\text { w, CS }\end{array}$ & $\begin{array}{l}\text { Klebsiella } \\
\text { pneumoniae } \\
\text { (pus) }\end{array}$ \\
\hline $\begin{array}{l}\text { Chen et } \\
\text { al, } 2008\end{array}$ & $\begin{array}{l}\text { Vaginal } \\
\text { GBS } \\
\text { infection } \\
\text { TVOR }\end{array}$ & $\begin{array}{l}28 \mathrm{w} \text { and } \\
4 \mathrm{~d}\end{array}$ & $29 \mathrm{w}$ and $2 \mathrm{~d}$ & $\begin{array}{l}\text { Laparotomy- CS, } \\
\text { right SO }\end{array}$ & $\begin{array}{l}\text { Healthy NB at GA } 29 \\
2 / 7 \text { w, CS }\end{array}$ & $\begin{array}{l}\text { E. coli, GBS } \\
\text { (cervical) }\end{array}$ \\
\hline
\end{tabular}




\begin{tabular}{|c|c|c|c|c|c|c|}
\hline Report & $\begin{array}{l}\text { Risk } \\
\text { factors }\end{array}$ & $\begin{array}{l}\text { Onset } \\
\text { GA }\end{array}$ & $\begin{array}{l}\text { Time of } \\
\text { intervention }\end{array}$ & $\begin{array}{l}\text { Surgical } \\
\text { intervention/ } \\
\text { procedure }\end{array}$ & $\begin{array}{l}\text { Maternal and } \\
\text { neonatal outcomes }\end{array}$ & Bacterial study \\
\hline $\begin{array}{l}\text { Craggs } \\
\text { et al } \\
(2009)\end{array}$ & $\begin{array}{l}\text { Endomet } \\
\text { riosis, } \\
\text { pelvic } \\
\text { surgery }\end{array}$ & $30 \mathrm{w}$ & $\begin{array}{l}30 \mathrm{w} \text { and } 5 \mathrm{~d} \\
31 \mathrm{w} \text { and } 3 \mathrm{~d}\end{array}$ & $\begin{array}{l}\text { Laparotomy- } \\
\text { appendectomy, drain } \\
\text { placement } \\
\text { Laparotomy-CS, } \\
\text { right SO }\end{array}$ & NB at GA $313 / 7 \mathrm{w}, \mathrm{CS}$ & $\begin{array}{l}\text { E. coli, } \\
\text { Veillonella } \\
\text { parvula, } \\
\text { Bacteroides } \\
\text { fragilis, }\end{array}$ \\
\hline
\end{tabular}

Note: m: months, w: weeks, d: days, CS: Cesarean section, NB: Newborn baby, GA: Gestational age, SO: Salpingo-oophorectomy, TVOR: Transvaginal oocyste retrieval.

\section{CONCLUSION}

In summary, PID associated with OA may occur in pregnancy, in spite of its rarity. This complication is more likely in the $1^{\text {st }}$ trimester, but also common in $3^{\text {rd }}$ trimester. An awareness of detailed medical history and physical examination are needed to obtain an accurate diagnosis and prompt treatment, which are mandatory for good pregnancy outcome. Delayed recognition and inappropriate intervention may lead to materno-fetal death. Therefore, obstetricians should carefully monitor the ovarian abscess. This disease should be a differential diagnosis of lower abdominal pain in pregnancy. The surgical approach is aggressive radical surgery, but conservative management could also be prioritized to avoid unnecessary interventions. Surgical modalities should be considered carefully if the condition progresses or persists after conservative medical treatment.

\section{ACKNOWLEDGMENTS}

Authors would like to thank Collegues, Department of Gynecological Clinic Unit, Department of Imagine Diagnostic, Department of Endoscopy, and Department of histopathology for their support during study.

Funding: No funding sources

Conflict of interest: None declared

Ethical approval: Not required

\section{REFERENCES}

1. Revzin MV, Mathur M, Dave HB, Macer ML, Spektor M. Pelvic Inflammatory Disease: Multimodality Imaging Approach with Clinical-Pathologic Correlation. Radiographics. 2016;36(5):1579-96.

2. Brandão P, Portela-Carvalho A, Estevinho C, Soares E, Melo A. Tubo-Ovarian Abscess in Early Pregnancy - Report of a Rare Coexistence. Obstetr Gynaecol Cases - Rev. 2018;5.

3. Kairys N, Roepke, C. Tubo-Ovarian Abscess. StatPearls. 2021.

4. Hoffman BL, Schorge JO, Schaffer JI, Halvorson LM, Bradshaw KD, Cunningham FG. Pelvic inflammatory disease. Williams Gynecology. 2nd ed. New York, NY: McGrawHill; 2012.
5. Bereck JS, Novak E. Pelvic pain and Dysmenorrhea. Bereck and Novak's Gynecology. 15th ed. Philadelphia, PA: Lippincott William; 2012.

6. Lee H, Kim Y, Kim CH, Song T, Lee K. A case of tubo-ovarian abscess in a pregnant woman. Korean $\mathrm{J}$ Obstet Gynecol. 2012;55:843.

7. Jafari K, Vilovic-Kos J, Webster A, Stepto RC. Tuboovarian abscess in pregnancy. Acta Obstet Gynecol Scand. 1977;56:1-4

8. Sherer DM, Schwartz BM, Abulafia O. Management of pelvic abscess during pregnancy: a case and review of the literature. Obstet Gynecol Surv. 1999;54(10):655-62.

9. Davey MM, Guidozzi F. Ruptured tubo-ovarian abscess late in pregnancy. A case report. S Afr Med J. 1987;71(2):120-1.

10. Hernández LH, Serrano LG, Piñeyro MO, Martinez A, Orozco MC, Gonzalez G. Comparative study of the clinical features of patients with a tubo-ovarian abscess and patients with severe pelvic inflammatory disease. Int J Gynaecol Obstet. 2016;132(1):17-9.

11. Yalcin OT, Tanir HM, Eskalen M. Unruptured pelvic abscesses in pregnancy: report of two cases. Gynecol Obstet Invest. 2002;53(2):133-4.

12. Hakoun AM, Shaar I, Zaza KJ, Shaar H, Salloum MN. Adnexal masses in pregnancy: An updated review. Avicenna J Med. 2017;7(4):153-7.

13. Taylor GM, Erlich AH, Wallace LC, Williams V, Ali RM, Zygowiec JP. A tubo-ovarian abscess mimicking an appendiceal abscess: a rare presentation of Streptococcus agalactiae. Oxf Med Case Reports. 2019;2019(8):omz071.

14. Kazemi SN, Raoufi M, Samsami M, Didar H, Najafiarab H. A case-report on diverticulitis misdiagnosed as tubo-ovarian abscess. Ann Med Surg (Lond). 2021;72:103049.

15. Moshi SJ. Lower Abdominal Pain in the First Trimester of Pregnancy. Gyn Less Red Loc. 35-39.

16. Vimala NK, Mittal S, Kumar S, Dadhwal V. Primary Ovarian Abscess in Pregnancy. JK Sci. 2004;6:40-2.

17. Liu YZ, Li Wang. Laparotomy versus laparoscopy for the elective cystectomy of a benign ovarian tumour during pregnancy: a retrospective cohort study. Int J Clin Exp Med. 2017;10:10918-27.

18. Souza G. Ovarian abscess with spontaneous vaginal drainage. São Paulo Med J. 1997;115:1596-8.

19. Han C, Wang C, Liu XJ, Geng N, Wang YM, Fan AP, et al. In vitro fertilization complicated by rupture of 
tubo-ovarian abscess during pregnancy. Taiwan $\mathrm{J}$ Obstet Gynecol. 2015;54(5):612-6.

20. Jafari K, Vilovic-Kos J, Webster A, Stepto RC. Tuboovarian abscess in pregnancy. Acta Obstet Gynecol Scand. 1977;56(1):1-4.

21. Cho HW, Koo YJ, Min KJ, Hong JH, Lee JK. Pelvic Inflammatory Disease in Virgin Women With Tuboovarian Abscess: A Single-Center Experience and Literature Review. J Pediatr Adolesc Gynecol. 2017;30(2):203-8.

22. Abdou R, Miller T. Postpartum tubo-ovarian abscess, likely arising from pelvic inflammatory disease during pregnancy. BMJ Case Rep. 2017;2017:bcr2017220183.

23. Nkwabong E, Fomulu JN. Tubo-Ovarian Abscess During Pregnancy: A Case Report. Int J Gynecol Obstetr. 2013;17:1-3.

24. James AN, Knox JM, Williams RP. Attachment of gonococci to sperm. Influence of physical and chemical factors. Br J Vener Dis. 1976;52:128-35.

25. Kolb BA, Mercer L, Peters AJ, Kazer R. Ovarian abscess following therapeutic insemination. Infect Dis Obstet Gynecol. 1994;1(5):249-51.

26. Matsunaga Y, Fukushima K, Nozaki M, Nakanami N, Kawano Y, Shigematsu T, et al. A case of pregnancy complicated by the development of a tubo-ovarian abscess following in vitro fertilization and embryo transfer. Am J Perinatol. 2003;20(6):277-82.

27. Moradan S. A ruptured tubo-ovarian abscess after intrauterine insemination; a case report. Iranian $\mathbf{J}$ Reprod Med. 2009;7.

28. Biringer K, Zubor P, Visnovsky J, Danko J. Delayed delivery following unusual flare-up pelvic abscess after in vitro fertilization and embryo transfer. Fertil Steril. 2009;91(5):1956-7.

29. Mokdad C, Rozsnayi F, Delaunay F, Gregorczyk V, Auber M, Puscasiu L, et al. Surgical treatment of tuboovarian abscess occurring in deep endometriosis. Gynecol Obstetr Fertil. 2010;38:490-5.

30. Habek D, Has B, Habek JC. Tuboovarian abscess mimicking intraligamentar uterine myoma and a intrauterine device: a case report. Eur J Contracept Reprod Health Care. 2005;10(3):168-70.

31. Oshina K, Ozaki R, Kumakiri J, Murakami K, Kawasaki Y, Kitade M, et al. Pyomyoma mimicking tubo-ovarian abscess: Two case reports. Case Rep Womens Health. 2021;33:00372.

32. Erdem M, Arslan M, Yazici G, Erdem A, Gursoy R. Incidental tubo-ovarian abscess at abdominal delivery: a case report. J Matern Fetal Neonatal Med. 2002;12(4):279-80.

33. Velcani A, Conklin P, Specht N. Sonographic features of tubo-ovarian abscess mimicking an endometrioma and review of cystic adnexal masses. J Radiol Case Rep. 2010;4(2):9-17.

34. Navada HM, Bhat BP. Pelvic inflammatory disease in the form of peritoneal abscess complicating late pregnancy. Case Rep Obstet Gynecol. 2011;2011:851598.
35. Bauer ME, Price LK, MacEachern MP, Housey M, Langen ES, Bauer ST. Maternal leukocytosis after antenatal corticosteroid administration: a systematic review and meta-analysis. J Obstet Gynaecol. 2018;38(2):210-6.

36. Arbib N, Aviram A, Gabbay R, Sneh O, Yogev Y, Hadar E. The effect of labor and delivery on white blood cell count. J Matern Fetal Neonatal Med. 2016;29(18):2904-8.

37. Gowri V, Zaabi MA, Hosni MKA. Clinical usefulness of white blood cell count in detecting infection in postpartum women. European J Obstetr Gynecol Reprod Biol. 2016;206:7.

38. Katherine R. Birchard MAB, W. Brian Hyslop, Zeynep Firat, Richard C. Semelka. MRI of Acute Abdominal and Pelvic Pain in Pregnant Patients. AJR. 2005; 184:452-8.

39. Leiserowitz GS, Xing G, Cress R, Brahmbhatt B, Dalrymple JL, Smith LH. Adnexal masses in pregnancy: how often are they malignant? Gynecol Oncol. 2006;101(2):315-21.

40. Celik H, Celik E, Yasa C, Yuksel S, Celik S, Dural O, et al. Different Management Options for TuboOvarian Abscess: A Tertiary Referral Center Experience. Med J Okmeydani Train Res Hospital. 2017.

41. Chan GMF, Fong YF, Ng KL. Tubo-Ovarian Abscesses: Epidemiology and Predictors for Failed Response to Medical Management in an Asian Population. Infect Dis Obstet Gynecol. 2019;2019:4161394.

42. Akca A, Bac G. Routine Surgical Drainage in Tuboovarian Abscess: Single Center Experience with Fifty Patients. J Immunol Clin Microbiol. 2019;4:52-8.

43. Sartelli M, Chichom-Mefire A, Labricciosa FM, Hardcastle T, Abu-Zidan FM, Adesunkanmi AK, et al. The management of intra-abdominal infections from a global perspective: 2017 WSES guidelines for management of intra-abdominal infections. World J Emerg Surg. 2017;12:29.

44. Nezhat F, Nezhat C, Silfen SL, Fehnel SH. Laparoscopic ovarian cystectomy during pregnancy. J Laparoendosc Surg. 1991;1(3):161-4.

45. Shigemi D, Matsui H, Fushimi K, Yasunaga $H$. Laparoscopic Compared With Open Surgery for Severe Pelvic Inflammatory Disease and TuboOvarian Abscess. Obstet Gynecol. 2019;133(6):122430.

46. Duarte R, Fuhrich D, Ross JD. A review of antibiotic therapy for pelvic inflammatory disease. Int $\mathrm{J}$ Antimicrob Agents. 2015;46(3):272-7.

47. Bookstaver PB, Bland CM, Griffin B, Stover KR, Eiland LS, McLaughlin M. A Review of Antibiotic Use in Pregnancy. Pharmacotherapy. 2015;35(11):1052-62.

48. Melamed N, Baschat A, Yinon Y, Athanasiadis A, Mecacci F, Figueras F, et al. FIGO (international Federation of Gynecology and obstetrics) initiative on fetal growth: best practice advice for screening, 
diagnosis, and management of fetal growth restriction. Int J Gynaecol Obstet. 2021;152:3-57.

49. Fetal Growth Restriction. ACOG Practice Bulletin, Number 227. Obstet Gynecol. 2021;137(2):16-28.

50. Kinay T, Unlubilgin E, Cirik DA, Kayikcioglu F, Akgul MA, Dolen I. The value of ultrasonographic tubo-ovarian abscess morphology in predicting whether patients will require surgical treatment. Int $\mathbf{J}$ Gynaecol Obstet. 2016;135(1):77-81.
51. Akkurt MÖ, Yalçın SE, Akkurt İ, Tatar B, Yavuz A, Yalçin Y, et al. The evaluation of risk factors for failed response to conservative treatment in tubo-ovarian abscesses. J Turk Ger Gynecol Assoc. 2015;16(4):226-30.

Cite this article as: Vuong ADB, Nguyen PN. An extremely rare case of ovarian abscess in third trimester of pregnancy managed by successful vaginal birth and review of literature. Int J Reprod Contracept Obstet Gynecol 2022;11:924-34. 